\title{
Tools for a large-scale seismic assessment method of masonry cultural heritage
}

\author{
C. Limoge Schraen ${ }^{1}$, C. Giry ${ }^{1}$, C. Desprez ${ }^{2} \&$ F. Ragueneau ${ }^{1}$ \\ ${ }^{1}$ LMT-Cachan UMR 8535 - ENS Cachan, CNRS, \\ Université Paris-Saclay, France \\ ${ }^{2}$ IFSTTAR, Marne la vallée, France
}

\begin{abstract}
The preservation of architectural heritage against natural hazards, especially seismic risks, is extremely challenging. Countries presenting a medium seismic risk like France still want to protect this particularly sensitive but also numerous heritage. Our research work therefore seeks to meet those two requirements. Firstly the large-scale of the study deals with a large number of buildings to be diagnosed across the studied region. Furthermore we need to propose a relevant analysis of the seismic behaviour of masonry historic structures, by inexpensive ways. We rely on studying the rich heritage of vernacular Baroque churches and chapels in the highest valleys of French Savoye. We first present the choices we made and the tools we developed to meet the identified requirements. Then we develop how we used ambient noise measurements in order to calibrate and validate initial models of unfamiliar complex structures. Finally we explain how we defined a damage threshold criterion by comparing different approaches, numerical and kinematics.
\end{abstract}

Keywords: masonry, seismic vulnerability, ambient vibrations testing, numerical modelling.

\section{Seismic assessment of cultural heritage: key issues}

The preservation of architectural heritage against natural hazards, including seismic, poses many challenges as will be illustrated on a rural architectural heritage of great value: churches and chapels of the 17th and 18th centuries of the High valleys of the French Savoy. This Savoyard Baroque was born in a very active period from the political, economic and religious point of view, leading to 
a proliferation of projects either built from scratch, resulting in very homogeneous buildings or modification of earlier buildings, leading to more composite ones. Furthermore this region is largely located in zone 4 of the new seismic zoning, therefore having the largest metropolitan hazard with a maximum acceleration of a reference to the rock $\mathrm{g}=1.6 \mathrm{~m} / \mathrm{s} 2$.

Countries of medium seismic risk, such as France and Switzerland [1] wish to protect their built cultural heritage, which requires the development of methods adapted to areas with moderate seismicity, where the consideration of seismic risk in a systematic manner for existing buildings is fairly recent, and lacking of database of in-situ damage. In addition, a large part of this heritage, as it is the case here, consists of vernacular architecture, using rustic materials and often poorly maintained. These fragile structures contain a very rich furniture and pictorial heritage (Fig. 1), whose preservation implies building integrity. On the other hand, the major part of the buildings, as here, is made with masonry, a complex material hard to know even with a significant investment [2]. Note also that for the diagnosis of a complete heritage, concerned buildings are numerous. It is therefore impossible to treat them one by one without leaving some of them out arbitrarily from the start. Finally, there are specific problems with the historic buildings $(\mathrm{CuHeS})$ which are subjected to the regulatory requirements even for in situ tests, with legibility, compatibility and reversibility requirements for every intervention (Venice Charter, [3]).
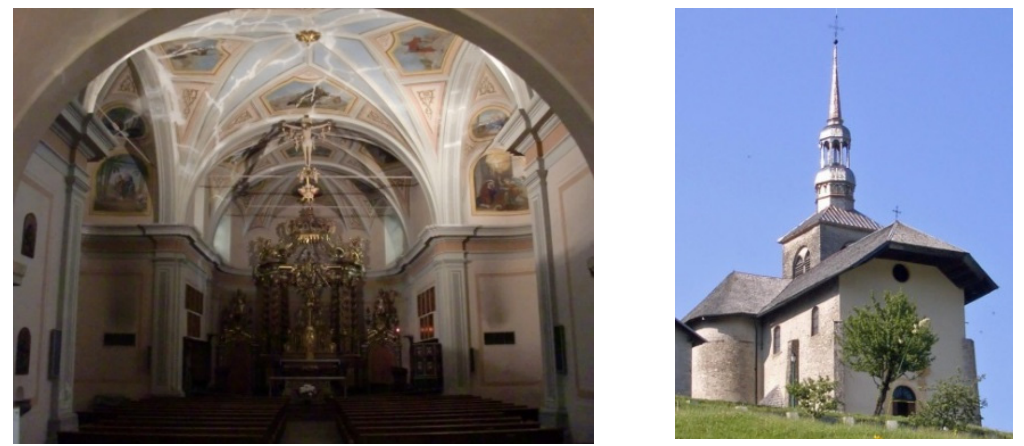

Figure 1: Church of Saint-Nicolas-la-Chapelle: interior and exterior.

To meet these challenges, we seek to propose a method for large-scale seismic vulnerability analysis. This diagnostic method, based on Finite Element (FE) numerical modelling of historic buildings and their seismic behaviour, rests on hierarchized levels of modelling: linear for the all buildings and more detailed nonlinear for structures showing a high level of risk in the linear analysis.

Given the strong constraints above outlined, our approach must meet two main requirements:

- Provide relevant analysis of the seismic behaviour of historic masonry structures

- Contain the number of numerical models necessary for the diagnosis of a large number of buildings. 
In this paper we present the frame of our strategy. Firstly we explain all the choices we have made and the tools we have developed to meet the identified requirements: grouping the many churches in a few structural types, selecting the modelling assumptions adapted to the specificities of the panel. We will insist on the pre-processor we made to build meshes for FE calculations of complex structures. Then we develop the use of the actual vibratory behaviour of our complex buildings for updating and validating our models. Finally we explain how we defined a damage threshold criterion by comparing two numerical approaches, linear and non-linear, with the non-linear kinematic analysis.

\section{Development of a typological classification}

Analysing the archives allowed us to identify the relevant panel: 198 chapels and churches built or heavily modified between 1615 and 1792 ([4], Fig. 2). To provide a diagnosis of all these buildings, it is imperative to develop appropriate tools at this scale. Geometric criteria have been proposed in this prospect [5]. But then we cannot assess the expected level of damage or the behaviour of the structure under earthquake, crucial information for reinforcement. We chose to use the vulnerability curves method, perfectly suited to this scale. This probabilistic approach used for modern structures as for cities [6] defines a level of damage on a global criterion.

These curves give information for a class of structures with the same structural characteristics. We conducted a survey campaign on all buildings and established a database [4]. Starting from the EC8 and the Italian recommendations for $\mathrm{CuHeS}$ [7], we have defined five structural characteristics leading to seismic fragility: plan type, discontinuity between nave and choir, number and shape of nave(s), tribune, and choir shape. This allowed us to define from our panel the seven types of buildings, depicted in Fig. 2.

\section{3D meshing and. geometric variability of identified typologies: MicMac software and pre-processor}

We use the finite element code Cast $3 \mathrm{M}$ for numerical studies. Building directly the mesh in the FE code of a lot of irregular structures would not be very manageable. This would limit computation on structural, geometrical or settlement variations. Therefore we developed a pre-processing program in order to get a full parameterized model from the geometric data, including ground and geometry special features. Lacking of existing detailed plans, it is based on in situ photogrammetric surveys using a Canon $50 \mathrm{D}$, lenses 16 and $50 \mathrm{~mm}$ and the MicMac software from the IGN (Fig. 3(a)). The structure's plan is split up into X, $\mathrm{Y}, \mathrm{Z}$ or angled oriented plans, and then each plan is divided into homogeneous structural zones separated by vertical or horizontal lines: façade's limits, inside and outside ground, tribune... Indications about the ground slope are given by four relevant points (Fig. 6), determining the zones of the structure in contact with the soil. This process allows building complex geometries for all religious buildings 


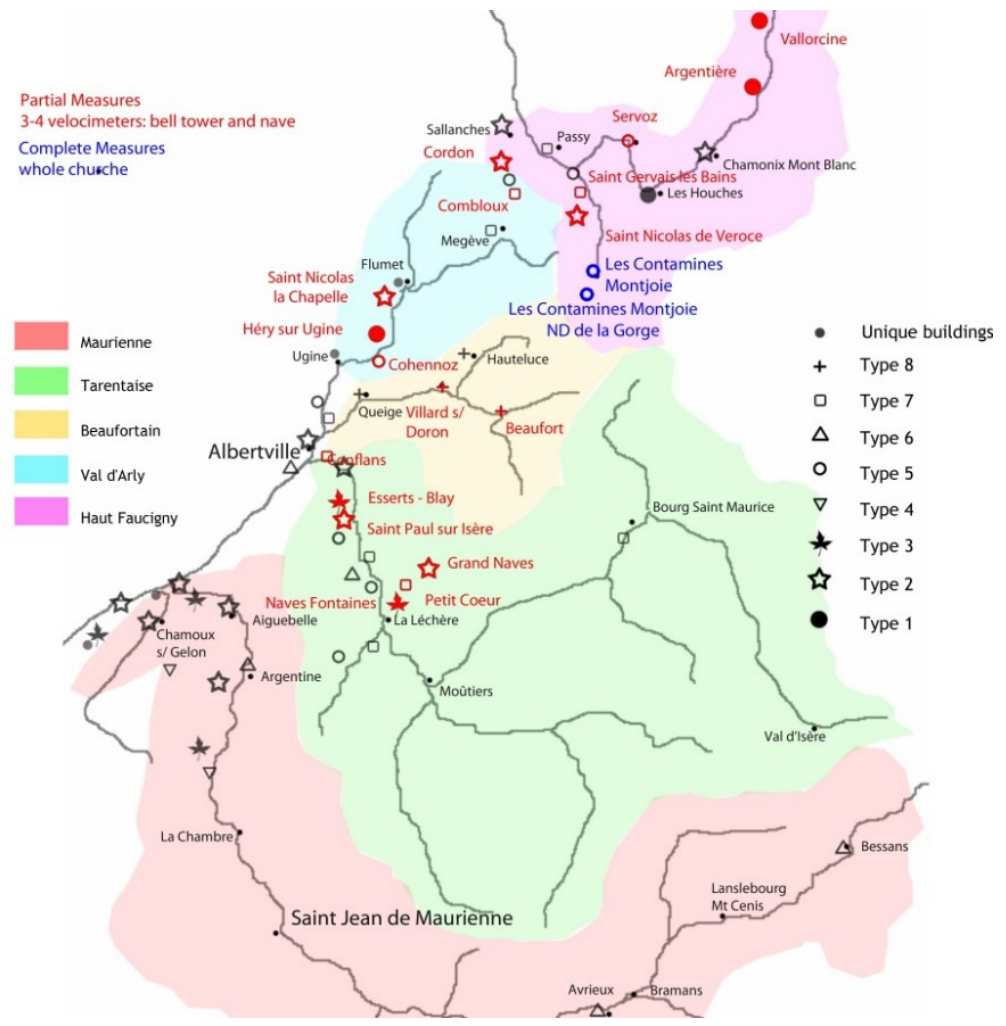

Figure 2: Structural types of the 70 churches and vibration measurements.

types (Fig. 3(b)) but also every variations on the most representative model of each type (Fig. 3(c)), which is crucial for vulnerability studies.

\section{Modelling assumptions for specific elements}

The masonry of our buildings is quite crude, highly heterogeneous and more isotropic than paired masonry presenting preferred crack directions, so we use a macro-modelling, on shell elements. This alleviates the model and the construction of parameterized meshes. The mechanical properties of linear initial models are taken from the literature $[7,8]$.

The geometry and the implementation of the buildings require sometimes complex assumptions and control of their validity domains in order to achieve a simplified but relevant model regarding the results to be obtained. We identified three areas that concentrate the largest possible variations, namely foundations, vaults and beams [4]. A parametric study of different choices of models allowed us to quantify the results in terms of the impact stiffness, deformation and modal natural frequencies. We were able to determine, according to the structure types, 


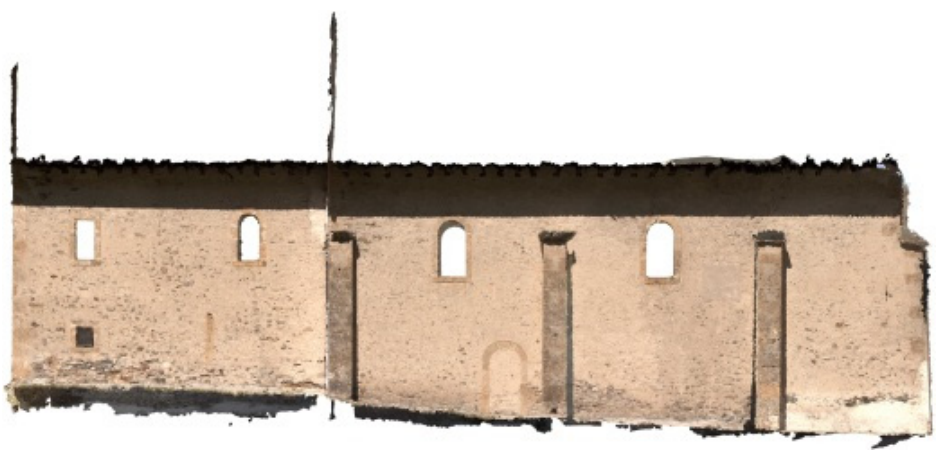

(a)

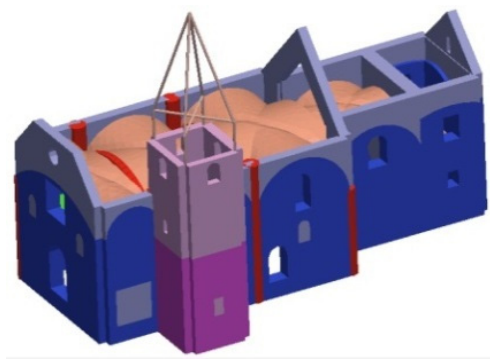

(b)

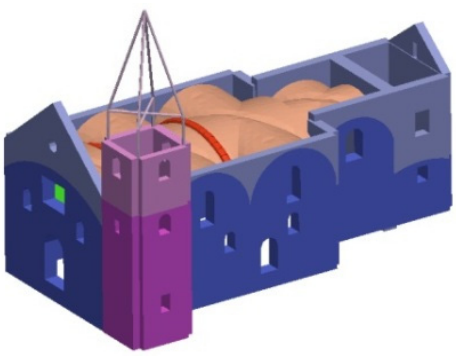

(c)

Figure 3: Notre-Dame-de-la-Gorge: (a) Facade survey, MicMac, (b) Cast3M mesh and its sub-structures, (c) variation on the same structural type for another mesh.

the most appropriate model assumptions. Moreover, in order to take into account the materials and geometric characteristics of macro-elements, we divided each building into substructures. Notre-Dame-de-la-Gorge (Fig. 3(b)) is thus described by three kinds of walls by thicknesses, a set of pilasters, buttresses and arches modelled by beam elements, the tribune with a specific construction method, the base of masonry tower which is paired, and the vaults.

\section{Validation of the numerical model with in-situ measurements}

The ambient noise measurement is developed for a couple of years to record the vibration characteristics of a structure, especially for slender structures such as towers, both for one-time diagnosis and monitoring [9]. The modal parameters, natural frequencies, mode shapes and damping of a structure are extracted from the records of its vibrations. Then minimizing the frequency and/or mode shape differences between numerical models and experimental information allows determining the unknown variables. These parameters can be geometric boundary conditions, thicknesses - or mechanical - Young's modulus (E), density 
( $\rho)$. We used this method on our complex buildings. After in-situ vibration measurements, we developed a method to progressively update the initial numerical model. We start from partial measures on a macro-element, like the tower, in order to define the most basic parameters, and then we split the structure into parts with very different modes to update them with more specific parameters, before reassembling all parts for a final update.

\subsection{Ambient noise vibrations measurements}

We made measures in twenty churches from six different structural types (Fig. 2) in collaboration with P. Gueguen, laboratory ISTerre, Grenoble, France. Measurements are limited to two sets in bell tower and a nave span, or extended to the whole building using thirty sensors on four levels (Fig. 4). We choose the most representative buildings of their structural type, distributed in the whole study area, avoiding too specific situations.

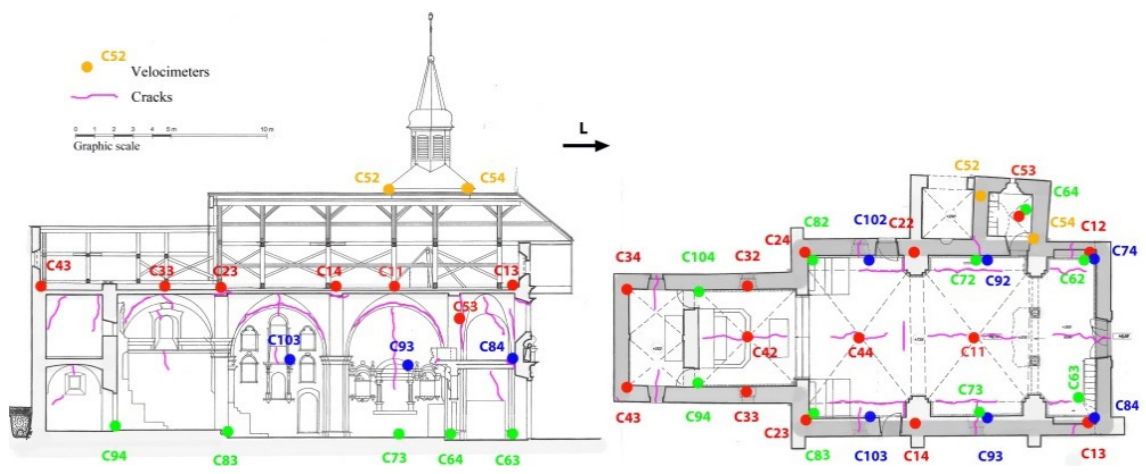

Figure 4: Plan and section with raised cracks (MicMac) position sensors.

Solicitations are the ambient vibrations coming from wind effects, human activities or natural and anthropogenic transient movements. They present a white noise in the $0.5-20 \mathrm{~Hz}$ band, relevant to our buildings. We used 4 velocimeters LE-3D 3Dlite MkIII with a high sensitivity in the $0.4-25 \mathrm{~Hz}$ band. They are just placed on the test structure. The digitizer is a station Cityshark II, low noise, with sufficient amplitude saturation for ambient vibrations. The equipment runs on batteries, so suitable for large and isolated buildings.

For operational modal analysis, we used the Enhanced Frequency Domain Decomposition Method (EFDD) that allows us to isolate modes and calculate their damping using the Modal Assurance Criterion (MAC), which compares two modal bases. The principle of this method is to decompose the spectral densities of matrices in independent degrees of freedom due to the singular value decomposition (SVD) [6].

For every bell towers, recorded resonance frequencies differ by less than $15 \%$ from the computed ones. The measures evidence the geometric characteristics of structures. The bell tower of Beaufort, stocky and built in the nave on a large part 
of its height, presents higher frequencies and smaller amplitudes than Conflans (see Fig. 5). Studying the nave shows similar behaviours: the low frequencies and high amplitudes seen in Conflans are due to a slender and longer body and tribune limited to a portion of the first span unlike the $\mathrm{U}$ shaped tribune in Beaufort. This shows the importance of the irregularity of the plan, the slenderness of the walls and the position of the tribune.

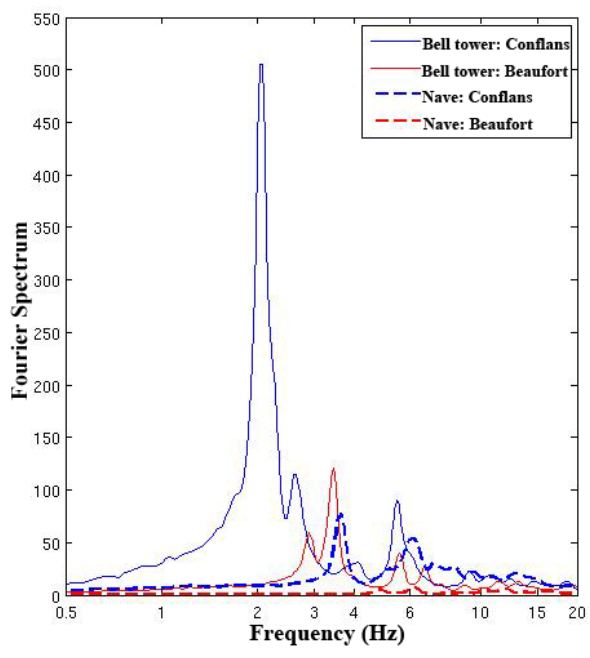

\begin{tabular}{|c|c|c|c|}
\hline \multicolumn{2}{|c|}{ Titulature } & Saint & $\begin{array}{c}\text { Saint } \\
\text { Maxime }\end{array}$ \\
\hline \multirow{6}{*}{ Tower } & width (m) & 8 & 4.3 \\
\hline & length (m) & 8.5 & 4.5 \\
\hline & height $(\mathrm{m})$ & 31 & 15 \\
\hline & Max & & \\
\hline & $\begin{array}{c}\text { Fourier } \\
\text { Spectrum }\end{array}$ & 505.7 & 120.9 \\
\hline & $\begin{array}{c}\text { Frequency } \\
\mathrm{X}(\mathrm{Hz})\end{array}$ & 2.067 & 3.467 \\
\hline \multirow{5}{*}{ Nave } & width (m) & 16 & 13 \\
\hline & length $(\mathrm{m})$ & 38 & 23 \\
\hline & height $(\mathrm{m})$ & 10.5 & 7.8 \\
\hline & $\begin{array}{c}\text { Max } \\
\text { Fourier } \\
\text { Spectrum }\end{array}$ & 77.71 & 7.088 \\
\hline & $\begin{array}{c}\text { Frequency } \\
\mathrm{X}(\mathrm{Hz})\end{array}$ & 3.633 & 6.167 \\
\hline
\end{tabular}

Figure 5: Bell tower and nave of the churches Saint-Maxime in Beaufort (structural type 8) and Saint-Grat in Albertville-Conflans (structural type 7): Comparison of Fourier spectra - dimensions.

\subsection{Partial measures on bell towers: evaluation of mechanical properties}

Modelling the bell tower is simpler than the nave due to the smaller number of unknowns. In addition, ambient noise measurements are particularly effective for this type of work [10]. Considering the characteristics of materials as variables to update the model in frequency, we can determine a range of mean mechanical characteristics adapted to the region [11]. We chose to measure $\mathrm{E}$ and $\rho$ by using them as optimization parameters. To perform this adjustment, we use the above defined error function, starting from the frequencies in $\mathrm{X}$ and $\mathrm{Y}$ directions measured (exp) and calculated (num):

$$
\text { Errtot }=\sqrt[2]{\frac{\left(\mathrm{FX}_{\exp }-\mathrm{FX}_{\text {num }}\right)^{2}}{\mathrm{FX}_{\exp }^{2}}+\frac{\left(\mathrm{FY}_{\exp }-\mathrm{FY}_{\text {num }}\right)^{2}}{\mathrm{FY}_{\exp }^{2}}}
$$

The minimization of this function by changing the material parameters allows us to determine the optimal characteristics. For this we use the "GRENAT" tool developed at LMT, based on a genetic algorithm. For $\mathrm{n}$ unknowns the number of 
trial tests needed is of the order of $2 \mathrm{n}$, hence the interest of reducing $\mathrm{n}$. This step allowed us to draw different conclusions:

- This updating method is fast and efficient, usable on a complete structure.

- On five different models of the same tower, with the same material parameters, the frequency differences exceed $25 \%$. This shows the importance of defining the initial FE model, especially to describe the interaction bell tower/nave and to take into account the roof and bells.

- We succeeded in defining $E$ and $\rho$ values appropriate to the masonry of this region and each building, by updating in frequency 17 models of towers, with less than $5 \%$ error on each.

- The structural types defined above (see Fig. 2) appear validated inasmuch as 3 categories only emerge from the $\mathrm{E} / \mathrm{\rho} /$ Height ratio. The first contains rich buildings in the Chamonix valley belonging to types 1-7. A second one concerns the poorest buildings of homogeneous construction in Beaufortain from types 5-8. Last one find poor structures in Tarentaise from types 2-3.

\subsection{Complete measures: identification and modal updating of numerical models}

The Notre-Dame-de-la-Gorge church is completely isolated, on a very flat area at the end of a glacial valley. Built in a single phase from 1699 to 1701, it belongs to the 5th structural type (Fig. 2 and 6). We noted thanks to the archives three series of structurally important work: At the end of the 19th century, the top of the bell tower, bays in the nave, bell tower and sacristy are changed; in 1990 and 2012, heavy repairs to the wood frame and roof, and a repair of the decorations are made, but cracks are visible again. It is built in rough masonry, with a significant proportion of mortar and stones of very irregular shape. No special pairing of stones is visible, except to the base of the tower.

Note that the AUTOMAC matrix of the experimental measurements allows defining the quality of MAC values to target. Indeed it indicates that some local modes are not recorded such as the oscillation of the gable in $\mathrm{Y}$ direction, which corresponds to the deformation of the 1st numerical mode. If the frequency pairing is good, the shape one remains quite bad because of a lack of sensors. The optimization will not solve this problem: MAC criterion will be lower for the first mode.

Preliminary results of the first model (cf. 3 and 4) without optimization are illustrated in Fig. 7. Mean MAC value of 0.65 over the first 4 modes shows a poor correlation. Indeed, the boundary conditions are poorly known because of a lack of data on the ground or foundations and because the rapid survey does not give enough information about the structural configurations. The average error frequency exceeds $10 \%$, due to a lower quality masonry of the facades than of the bell tower taken as a reference, and uncertainties in the mass of the roof of the nave and of the onion shaped roof of the bell tower. In addition, the MAC criterion is sensitive to extreme values, including those from the tower, the greatest because of its slenderness. They distort the results of the whole building. So we decided to 
split the model into two models: the nave and the bell tower, in order to update them separately.

We conducted these decoupled optimizations in three stages. We account for the missing part of the structure by filling the stiffness matrix of each model by introducing connection springs in the $\mathrm{X}$ and $\mathrm{Y}$ directions of appropriate stiffness, to the price of a slight increase of the computational cost, still tolerable for our light model. Conversely we introduced other new parameters for describing the foundations and the different types of masonry. Going from 3 to 35 parameters in the bell tower model, the average MAC value changes from 0.5 to 0.92 , allowing us to show the importance of the choice of parameters, because their multiplication is not acceptable. It makes the optimization more expensive, but is also misleading since we cannot control in situ the final values. So we then conducted a sensitivity analysis on all possible parameters for the nave (100) and the bell tower (52). The values of the mechanical properties then obtained are in the ranges of the Italian Code and literature. The Young's modulus and the stiffness's of supports present the least important density, leading us to retain the values of the optimization of the towers and the Italian code. Finally, it was we tested on a model of nave and tower six different error functions, combining the values of the spatial and frequency errors. Both indicators vary up to $35 \%$ for each mode depending on the chosen function. We must therefore adapt the function to the least known information in the structure we want to update. For the tower we give a higher weight to the spatial, MAC criterion, for the frequencies are already relevant, while bad shapes would be very detrimental to the overall MAC.

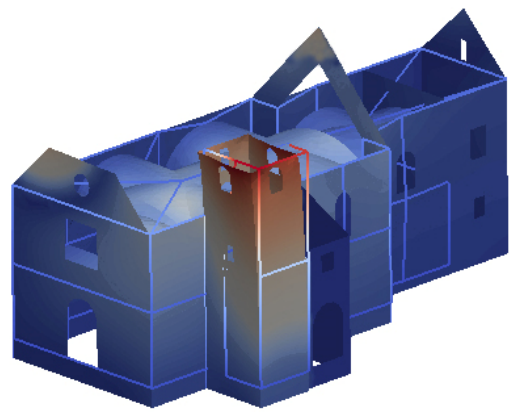

(a)



(b)

Figure 6: Notre-Dame-de-la-Gorge: 1srt Y bending mode before and after optimization. Experimental frequency: $5.99 \mathrm{~Hz}$. (a) numerical frequency: $4.52 \mathrm{~Hz}-\mathrm{MAC}$ : 0.64. (b) numerical frequency: $5.85 \mathrm{~Hz}-$ MAC: 0.97 .

Once the two parts have been separately updated, we combine them into a single one by introducing connections between them of appropriate stiffness's as deduced from the decoupling step. In this way, the updating of the complete model with 36000 elements is performed with a single parameter, the stiffness of the springs connecting the two parts, while several constraints optimizations were 
made on partial models. The final MAC criterion for the first four modes varies from 0.99 to 0.90 , showing a very good correlation. The frequency error varies from $0-9 \%$ with an average value of $5.4 \%$. The results are very satisfactory (see Fig. 6), especially for such a complex building.

\section{Definition of a damage criterion}

Vulnerability curves require threshold criteria, determining the damage level attained by the structure. The overall criteria used for modern buildings (interstage displacement) cannot be used for our structures. So we tested local failure criteria based on the stress level to draw broader cinematic criteria. We present the results for the tensile stress, using $\sigma t=1 \mathrm{E} 6 \mathrm{~Pa}$. The calculations are carried from the EC8 spectra: classes of buildings 4 and 3, Type II zone, soil category B, damping ratio of $5 \%$. The accelerogram is that of Irpinia, provided by the Permanent Accelerometric Network, and adjusted to the target spectrum. Then we compare the results to the information on failure mechanisms by macro-elements obtained from the kinematic analysis.

\subsection{Linear numerical model}

We built a map of the meshes where the stress criterion is violated. Then we compare this map to the damage surveys on the least-maintained structures of our panel, as well as with archival photographs and Italian codes. Included are structural degradation mechanisms of masonry in earthquake: roof thrust, discharge of gutter walls, vertical crack and spill of the facade. However, these observations need to be confirmed by other methods. Indeed the relevance of the conclusions of the linear model beyond the elastic limit is not granted, and churches are subjected to other stresses, such as landslides, that could cause visible damages unrelated to earthquakes.

\subsection{Non-linear numerical model}

The non-linear model of continuous damage used here [12], has been developed for large reinforced concrete structures. It relies on the assumption of a homogeneous and isotropic material throughout the structure. It is based on two damage variables, one in traction and the other in compression, and involves a strain tensor for characterizing the non-linear degradation mechanisms of the masonry. Silva et al. [13] shows that this model allows, on the scale of the structure, a better understanding of damage mechanisms.

Fig. 7 shows the zones without the vaults for the sake of clarity, in which the principal tension stress exceed the criterion both for the non-linear and linear models The areas are the same: gutter walls of the nave subjected to stresses outside the plan, pediments of the two end walls. However, they are wider in the non-linear model which takes into account the gradual accumulation of stresses. 


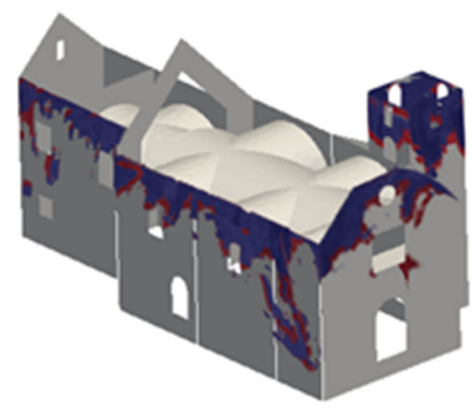

Figure 7: Notre-Dame-de-la-Gorge. SI11 areas beyond the threshold tensile criterion for nonlinear model (red) and linear (blue).

\subsection{Cinematic linear and non-linear analysis}

Many authors [14] agree on the fact that complex models, akin ours, don't always produce clear and reliable results. For structures such as churches, the Italian code recommends the kinematic analysis, either linear or nonlinear. In this approach, buildings are divided into parts which might have a local specific behaviour under earthquake, leading to local failure mechanisms. 28 different mechanisms are listed in the Italian code. Macro-element by macro-element, one determines all possible failure mechanisms in the church studied. Then, part by part, we calculate the value of the horizontal acceleration that triggers the possible mechanisms in relation to the damage limit state possible. This defines the horizontal action that the structure can withstand progressively during the development of the mechanism. Comparing this acceleration to the reference one of the site, one can determine the active mechanisms. For Notre-Dame-de-la-Gorge, a spill of the main facade is feared (Fig. 7): these mechanisms are not checked by neither the linear analysis nor the nonlinear one.

Table 1: Notre-Dame-de-la-Gorge. Kinematic analysis, main facade: mechanisms, ultimate and site accelerations.

\begin{tabular}{l|c|c|c}
\hline Mechanisms & $\begin{array}{c}\text { Ultimate } \\
\text { acceleration } \\
\left(\mathrm{m} / \mathrm{s}^{2}\right)\end{array}$ & $\begin{array}{c}\text { Site } \\
\text { acceleration } \\
\left(\mathrm{m} / \mathrm{s}^{2}\right)\end{array}$ & $\begin{array}{c}\text { Possible } \\
\text { mechanism }\end{array}$ \\
\hline Spill of the gable & 1.57 & 2.12 & yes \\
\hline Spill of the thinner upper parts & 0.747 & 0.962 & yes \\
\hline $\begin{array}{l}\text { Rotation of the facade with } \\
\text { parts of the orthogonal wall }\end{array}$ & 0.486 & 1.152 & yes \\
\hline
\end{tabular}

\section{Conclusions and perspectives}

We conducted the census and the survey of a vulnerable heritage, providing a coherent and extended study panel. We developed a method for simple models, thanks to the definition of structural types experimentally validated, the creation 
of tools for a fully parameterized meshing process of complex buildings and an impact assessment of the modelling choices in three key areas. We proposed a simple method to update on vibration measurements many different models from limited data, which can be so experimentally validated. We tested various stress damage criteria based on the first linear modelling step, and then also on a nonlinear model with the Faria model. We finally compared the results of FE models to those of the commonly accepted kinematic analysis, which allowed us to show that the results are in good agreement today, and that the criterion can be used for vulnerability curves.

We are now beginning to build the vulnerability curves, taking into account the variability of the seismic signal and geometry in a structural type. The next step will be the development of the following stages of the hierarchical method, transition to more sophisticated models with a non-linear model in areas of potential damage and building tests.

\section{References}

[1] Karbassi, A., and Lestuzzi P. Seismic risk for existing buildings in Switzerland - development of fragility curves for masonry buildings, EPFL, Lausanne, Switzerland, FOEN, (2014) p. 56.

[2] Valluzzi Mr, Da Porto F, Modena C. Structural investigation and strengthening of the Civic Tower in Vicenza. Proc. of Structural Faults and Repairs, London UK: 2003.

[3] ICOMOS, Principles for the Analysis, Conservation and Structural Restoration of Architectural Heritage, 14th General Assembly of ICOMOS, Victoria Falls, 2003.

[4] Limoge Schraen, C., Toward a large scale seismic assessment method for heritage building: Vulnerability of masonry baroque churches, European Journal of Environmental and Civil Engineering, 2015, accepted.

[5] Lourenço. P.B. \& Roque. J.A., "Simplified indexes for the seismic vulnerability of ancient masonry buildings", Construction and building materials, 20 (2006) pp. 200-208.

[6] Perrault M, Évaluation de la vulnérabilité sismique de bâtiments à partir de mesures in situ, Thèse de doctorat, Université de Grenoble, 2013.

[7] DPCM. Valutazione e riduzione del rischio sismico del patrimonio culturale con riferimento alle NTC 14 gennaio 2008. DPCM 9 febbraio 2011, G.U.R.I. February 26th 2011, Roma, Italy.

[8] Binda L, Tiraboschi C, Tongini Folli R. On site and laboratory investigation on materials and structure of a bell-tower in Monza Int. Zeitschrift fur Bauinstandsetzen und baudenkmalpflege 2000; 6(1): pp. 41-62.

[9] Gentile C, Saisi A., Ambient Vibration Testing of Historical Masonry Tower for Structural Identification and Damage Assessment Constr Build Mater, 21 (2007), pp. 1311-1321.

[10] Ivorra S, Pallarés Fj. Dynamic Investigations on a Masonry Bell Tower. Eng Struct 2006; 28: 660-667. 
[11] Russo G, Bergamo O, Damiani L, Lugato D. Experimental analysis of the "Saint Andrea" masonry bell tower in Venice. New method for the determination of “tower global Young's Modulus E”. Eng Struct 2010; 32: 353-360.

[12] Faria, R.; Oliver, J. \& Cervera, M. A strain-based plastic viscous-damage model for massive concrete structures International Journal of Solids and Structures, 1998, 35, 1533-1558.

[13] Silva, B.; Guedes, J. M.; Arêde, A. \& Costa, A. Calibration and application of a continuum damage model on the simulation of stone masonry structures: Gondar church as a case study Bull. Earthq. Eng, 2012, 10, 211234.

[14] Casarin, P. Structural assessment and seismic vulnerability analysis of a complex historical building. University of Trento, 2006. 